\title{
A PALESTRA EDUCATIVA NA ORIENTAÇÃO SOBRE O AUTOCUIDADO DO HIPERTENSO
}

\author{
Eliane Corrêa Chaves*
}

CHAVES, E.C. A palestra educativa na orientação sobre o autocuidado do hipertenso. Rev. Esc. Enf. USP, São Paulo, 24(3):397-402, dez. 1990.

Este estudo teve por objetivo a investigaşão da eficácia da palestra educativa como estratégia para veicular orientações sobre o autocuidado do hipertenso.

UNITERMOS: Hipertensão. Autocuidado.

\section{INTRODUÇÃO}

As medidas de manutenção à saúde e combate às doenças, associadas às modificações de hábitos de vida trouxeram como consequiência modificações no panorama epidemiológico das várias moléstias, particularmente das afecções crônicas que envolvem os individuos adultos ${ }^{5}$.

Dentre estas afecções crônicas, a hipertensão arterial tem merecido especial atenção dos profissionais de saúde, pois tem apresentado aumentos significativos na sua incidência, principalmente nos países onde ainda não existem programas de seguimento e controle da população acometida ${ }^{6}$.

Estudos realizados no Departamento de Epidemiologia da Faculdade de Saúde Pública da USP, analisando 2738 óbitos entre 15 e 74 anos, denıonstrou que $30 \%$ desta população era hipertensa. Dentre eles, $11,8 \%$ morreram por complicações diretas da hipertensão, 30,6\% devido a acıdente cérebro-vascular, $28,2 \%$ por doença isquêmica do coração e $29,2 \%$ por causas diversas ${ }^{3}$.

FRANCISCHETTI 8 afirma que a longevidade do ser humano está na relação inversa aos niveis de sua pressão arterial. Um homem de 35 anos cuja pressão arterial é de $150 \mathrm{~mm} \mathrm{Hg}$ por $10^{\circ} \mathrm{mm} \mathrm{Hg}$ poderá ter seu tempo de vida reduzido em 16,5 anos, se mantiver estes niveis não controlados.

A diminuiçăo cie longevidade rão é a única conseqüência indesejável da hipertensão arterial. As complicações que dela advém podem ser tão

\footnotetext{
- Enfermeira. Mestre em Enfermagem. Professora Assistente do Departamento de Enfermagem Médico-Cirúrgica da Escola de Enfermagem da Universidade de São Paulo - Disciplina Enfermagem Médico-Cirúrgica.
} 
ou mais desastrosas para o indivíduo afetado e para a sua família do que a própria morte.

GRESHAN at alii 9, em seus estudos em Framinghan, demonstrou que a hipertensão arterial é a principal precurssora da insuficiência carcíaca. Afirma também, que os hipertensos apresentam duas a quatro vezes mais infartos do miocárdio do que os normotensos e que são ainda quatro vezes mais propensos ao acidente cérebro vascular.

A hipertensão arterial tem sido amplamente citada como fator desencadeante das doenças cérebrovasculares ${ }^{3}$.

BRUUN et alii ${ }^{1}$ em seu estudo realizado com 328 pacientes pacientes acometidos por doença cérebrovascular aguda, observou que $50 \%$ deles eram hipertensos. CHAVES ${ }^{2}$, ao estabelecer um perfil dos pacientes internados por afecção cérebrovascular no Hospital das Clínicas da FMUSP, num período de oito anos, concluiu que 45,3\% deles eram hipertensos e caracterizou a hipertensão arterial como o fator de risco mais importante para esta afecção cerebral e aquele cujo controle pode trazer os resultados mais positivos na prevenção da doença cerebrovascular (DCV).

A estreita relação entre a hipertensão arterial e a DCV predispõe seus portadores às inúmeras adversidades conseqüentes às seqüelas advindas destas alterações cerebrais de origem vascular.

CHAVES ${ }^{2}$, em seu esíudo com 479 pessoas acometidas por DCV, constatou ainda que dentre os hipertensos que compunham este grupo, $29,5 \%$ evoluíram para o óbito durante a hospitalização e $66,0 \%$ dos sobreviventes foram vitimados por seqüelas físicas após o icto cerebral.

Estudos realizados por SHAFFER et alii 11 demonstraram que quase $100,0 \%$ da população acometida pelas doenças cérebrovasculares foram vitimas de seqüelas físicas de graus variados.

Estes resultados, em uma última análise, refletem a seriedảde do problema social, econômico e de saúde que a hipertensão arterial não controlada pode representar e a importância de manutenção da pressão arterial em niveis de normalidade, principalmente se considerarmos que isso pode ser suficiente para interromper o processo de degeneração vascular e suas conseqüências.

Sabemos, no entanto, que o controle da hipertensão arterial não é algo facilmente obtido. FINNERTY et alii 7 , por exemplo, identificou em sua clínica de hipertensão, $42,0 \%$ de abandono ao tratamento. CALDWELL et alii ${ }^{4}$, em estudo realizado em Michigan observou que 50,0\% do seu grupo de hipertensos abandonou o tratamento no decorrer de 11 meses de acompanhamento.

PIERIN 10, em trabalho desenvolvido na Liga de Diagnóstico e Tratamento de Hipertensão Arterial do Hospital das Clínicas da FMUSP, com 80 hipertensos, concluiu que vários são os fatores que dificultam a consecução deste objetivo, como por exemplo a falta de dinheiro para 
comprar os remédios, ou para comparecer às consultas e os efeitos colatcrais dos medicamentos. A estes fatores podemos incluir a inadequação dos programas de educação em saúde voltada para o auto cuidado do hipertenso.

A educação em saúde deve ser vista como importante estratégia para a promoção do auto cuidado do hipertenso, na medida que introduz ou reforça coriceitos e hábitos de proteção à saúde e permite o controle de agravos crônicos. Ela pode estimular, introduzir, facilitar ou manter práticas positivas que visam a manutenção da saúde.

O processo de educação em saúde assume ainda importante papel na valorização do indivíauo, uma vez que possibilita, estimula e até mesmo vincula seu êxito à participação de cada indivíduo na promoção, proteção e recuperação de sua saúde. Cada pessoa torna-se agente do processo e não mero receptor de assistência, ou seja, assume uma postura ativa, reflexiva em relação a seus comportamentos, a partir de novos conceitos que lhes pareçam convincentes e convenientes.

Como qualquer outro método de assistência, a eficácia da educação em saúde como método para veicular o autocuidado está intimamente relacionada à metodologia utilizada no seu planejamento e no seu desenvolvimento. Como seu resultado final, em última análise, visa a manutenção de comportamentos positivos em saúde e mudança dos adversos, torna-se claro, de certa forma, que não bastam conhecimentos técnicos dos profissionais de saúde e a utilização de métodos didáticos adequados para se obter resultados satisfatórios. A assimilação de novos conceitos e a mudança de comportamento dependem de mecanismos muito mais complexos do que pode supor um educador desatento ou descompromissado.

A educação em saúde não pode ser feita com base apenas no conhecimento que o educador tem do assunto sobre o qual vai discorrer, sob pena de ter o conteúdo esquecido imediatamente após sua apresentação ou algum tempo depois. Desta maneira, inviabiliza-se a mudança de comportamento, pois, para que ela ocorra é necessário que o educando assimile o conteúdo exposto, convença-se de seus benefícios para finalmente tentar viabilizá-lo na sua realidade cotidiana.

Delineia-se, portanto, uma seqüência de etapas que devem ser cumpridas e avaliadas individualmente, ou seja, a etapa seguinte inicia-se quando os resultados positivos da anterior forem comprovados por meio de métodos avaliativos.

Dentre estas etapas destacamos, como estratégia inicial, as palestras educativas, método que os profissionais de saúde dispöem para veicular conceitos científicos sobre o autocuidado. Para que estes conceitos sejam compreendidos e aceitos é necessário que haja consonância entre eles e os hábitos, crenças e valores existentes no grupo de educandos a qu se destina. Além disso, visando ainda obter resultados satisfatórios, ou seja, conseguir que os educandos absorvam grande parte do conteúdo exposto, nos parece conveniente que o tema a ser abordado na 
palestra educativa contenha aspectos de aplicabilidade imediata entre os educandos, isto é, traga respostas às necessidades sentidas pelo grupo.

Neste sentido, nos parece que as palestras dirigidas ao autocuidado do hipertenso é uma das situações que atende satisfatoriamente este objetivo por envolver um grupo de pessoas que freqüentemente tem conhecimento da cronicidade de sua afecção e da importâncía do seu controle na interceptação do processo evolutivo da doença.

Por tratar-se de um método que envolve pelo menos dois tipos de papéis, o de educando e o de educador, entendemos que o encaminhamento satisfatório de temas sobre o auto cuidado, além de responder às expectativas e necessidades dos educandos, deve estar apoiado no conhecimento, compromisso e crença do orientador sobre o tema. Acreditamos que, mesmo não intencionalmente, o educador tende a enfatizar os aspectos da palestra educativa que mais valoriza para o autocuidado. Tal situação, no entanto, pode resultar em confronto de crenças, hábitos e valores de pessoas (educador e educando) com referenciais em realidades distintas, o que possivelmente dificultará a consecução dos objetivos do orientador. Neste sentido, apesar das vantagens na utilização das palestras educativas sobre o autocuidado do hipertenso e da sua utilização já bastante freqüente, muitas dúvidas ainda permanerem no sentido de caracterizar sua efetividade como disseminadora de orientações específicas sobre esta doença.

Visando contribuir para o esclarecimento destas questões e abordando a importância do tratamento dietético, medicamentoso, da atividade física e dos hábitos de fumar e ingerir bebida alcoólica no controle da hipertensão arterial, este estudo se propõe a responder os seguintes objetivos:

- determinar o nível de conhecimento de um grupo de hipertensos quanto aos aspectos anteriormente citados, no controle da hipertensão arterial;

- analisar as modificações que podem ocorrer neste nível de conhecimento num intervalo de tempo imediato à mediato à ministração de uma palestra educativa sobre estes mesmos aspectos;

- verificar se a proporção de hipertensos que assimilaram o conhecimento sobre estes aspectos mantém equivalência com o grau de importância que lhes foi atribuído por um grupo de enfermeiras.

\section{MATERIAL E MÉTODO}

O estudo foi desenvolvido com 94 operários hipertensos de uma indústria metalúrgica, com escolaridade variando entre a primeira e a quirta série do $1^{\circ}$ grau.

$O$ fator a ser investigado neste estudo foi a absorção de informações obtidas a partir de palestras educativas ministradas pela pesquisadora. Nestas palestras foram enfocados aspectos relativos ao autocuidado do 
hipertenso, tais como: orientações dietéticas, atividades físicas, hábito de fumar, hábito de ingerir bebida alcoólica e tratamento medicamentoso.

A coleta de dados foi feita em três fases. A primeira, antes de qualquer intervenção do pesquisador; a segunda, imediatamente após esta intervenção e a terceira, dois meses depois.

O objetivo de cada uma das fases foi investigar o nivel de conhecimento da população sobre o autocuidado no controle da hipertensão arterial e estabelecer uma análise comparativa deste conhecimento nas três diferentes fases.

Esta análise comparativa, no entanto, se tornaria muito mais significativa na medida em que fosse investigada a assimilação das orientações voltadas para o autocuidado, não apenas no âmbito quantitativo, mas também qualitativamente. Para tanto, ou seja, para investigar a memorização de conhecimentos hierarquicamente mais significativos para o cuidado do hipertenso, foi elaborado, inicialmente, um instrumento com o conteúdo teórico da palestra educativa, apresentado sob a forma de itens.

Posteriormente, estes itens foram submetidos a apreciação por um corpo dejuízes composto por nove enfermeiras reconhecidas como conhecedoras do assunto, que atribuíram escores de 0 a 3 , de acordo com seus julgamentos. Os escores atribuídos pelos juízes aos itens e subitens da palestra educativa possibilitaram a elaboração de um referencial qualitativo, ou seja, de uma matriz que representou numericamente a importância que as enfermeiras atribuíram às orientações que foram dadas na palestra.

Com o propósito de investigar a efetividade da palestra educativa na veiculação quantitativa e qualitativa de informações, os dados obtidos foram analisados de duas formas. Na primeira, as entrevistas feitas com a população do estudo em três momentos diferentes e que caracterizaram três etapas distintas do conhecimento, foram comparadas entre si para determinar a quantidade de informações absorvidas e a constância desta memorização. Na segunda, a memorização das orientações sobre o auto cuidado foi analisada comparativamente com o referencial qualitativo estabelecido, a fim de verificar a eficácia da palestra educativa na sedimentação de informações consideradas importantes para o autocuidado do hipertenso. Os dados aqui obtidos, após comparações e análises, nos conduziu às seguintes conclusões:

- Considerando-se a primeira fase de conhecimento, ou seja, antes da intervenção educativa, foi possível constatar que $15,9 \%$ da população possuía informações corretas sobre a utilização do sal na dieta; $25,5 \%$ da população possuía informações corretas sobre a utilização da gordura animal na dieta; $30,3 \%$ da população sabia que a atividade física deve ser dimiuída por indicação médica; $75,5 \%$ sabia que o hábito de fumar deve ser abolido ou, pelo menos, diminuído; $74,5 \%$ possuía informações corretas a respeito do hábito de ingerir bebidas alcoólica e, $35,1 \%$ sabia que deveria procurar o médico caso a medicação utilizada lhe causasse problemas; 
- a palestra educativa única mostrou-se ineficaz para sedimentar informações importantes sobre o autocuidado, uma vez que não houve equivalência entre a valorização atribuída pelas enfermeiras e a proporção de hipertensos que assimilaram conhecimento.

CHAVES, E.C. The talk education to guide the self care in hypertension patient. Rev. Esc. Enf. USP, São Paulo, 24(3):397-402, Dec. 1990.

The purpose of this research is to study the value of health education class in the communication of the information on hypertension self care.

UNITERMS: Hipertension. Self care.

\section{REFERENCIAS BIBLIOGRAFICAS}

1. BRUUN, B. et alii. The epidemiology of stroke in central harlem. Stroke, New York, 4(3) :406-8, May/June 1983.

2. CHAVES, E.C. Fatores de risco em doencas cerebrovasculares: estudo retrospectivo com pacientes internados na Clínica Neurológica do Hospital das Clínicas da Faculdade de Medicina da USP entre 1977 e 1984. São Paulo, 1986. 75 p. (Dissertação de mestrado - Escola de Enfermagem da USP).

3. ChIAVerini, R. Doenca hipertensiva. Rio de Janeiro, Atheneu, 1980. 311 p.

4. CALDWELL, J.R. et alii. The dropout problem in antihypertensive treatment: a pilot study of social and emotional factors influencing a patient's ability to follow antihypertensive treatment. J. Chronic Dis., New York 22:579. 1970.

5. CAMARgo, C.A. O paciente de acidente vascular cerebral e os aspectos de enfermagem em reabilitação. Rev. Bras. Enf., Rio de Janeiro, 28(2):35-42, abr./jun. 1975.

6. CRUZ, J. Hipertensão arterial. Rev. Med., São Paulo, 59(6):181-205, dez. 1975.

7. FINNERTY. F.A. et alii. Hypertension in the inner city: analisis of clinic dropouts. Circulation, New York, 47:73, 1973.

8. FRANCISCHETTI, E.A. Alguns aspectos práticos no tratamento da hipertensão arterial em fase benigna. Ars Curandi, São Paulo, 1(6):6-28, dez. 1978.

9. GRESHAM, G.E. et alii. Residual disability in survivors of stroke: the framingham study. New Engl. J. Med., Boston, 293(19):954-6, Nov. 1975.

10. PIERIN, A.M.G. A pessoa com hipertensão arterial em tratamento no ambulatório: estudo sobre os problemas, dificuldades e expectativas quanto à doença e tratamento. Sño Paulo, 1985. 109 p. (Dissertação de mestrado - Escola de Enfermagem da USP).

11. SHAFER, S.O. et alii. The outcome of stroke at hospital discharge in New York city blaks. Stroke, New York 4(5):782-6, Sept./Oct. 1973.

Recebido em 06-11-89. 